
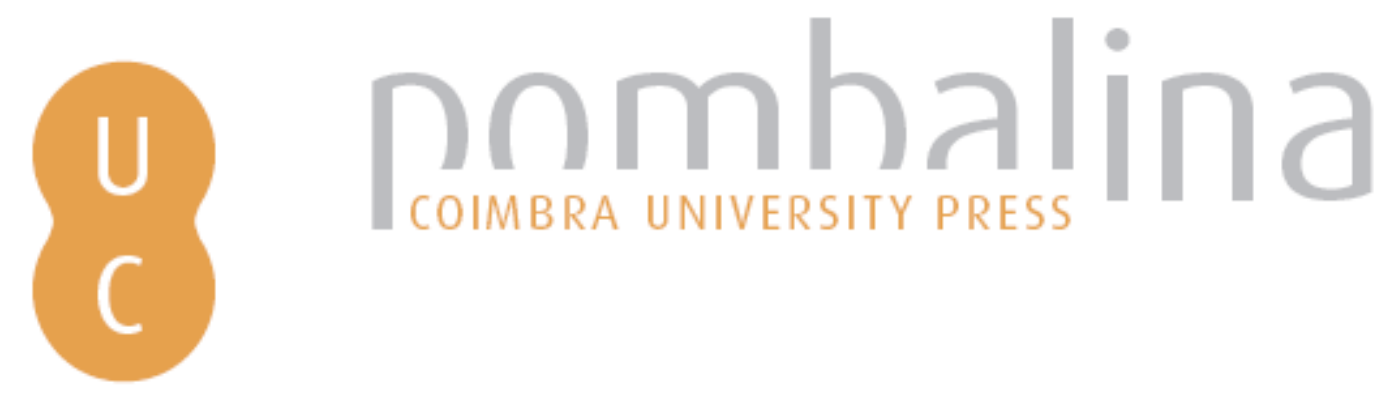

\title{
Integração e otimização de processos na indústria de prensados de madeira
}
Autor(es): $\quad$ Miranda, João; Seita, Ana; Fernandes, Cristina; Matos, Henrique A.; Nunes, Clemente Pedro

Publicado por: Imprensa da Universidade de Coimbra

URL

persistente: URI:http://hdl.handle.net/10316.2/35929

DOI: $\quad$ DOI:http://dx.doi.org/10.14195/978-989-26-0738-2_9

Accessed : $\quad$ 26-Apr-2023 01:31:39

A navegação consulta e descarregamento dos títulos inseridos nas Bibliotecas Digitais UC Digitalis, UC Pombalina e UC Impactum, pressupõem a aceitação plena e sem reservas dos Termos e Condições de Uso destas Bibliotecas Digitais, disponíveis em https://digitalis.uc.pt/pt-pt/termos.

Conforme exposto nos referidos Termos e Condições de Uso, o descarregamento de títulos de acesso restrito requer uma licença válida de autorização devendo o utilizador aceder ao(s) documento(s) a partir de um endereço de IP da instituição detentora da supramencionada licença.

Ao utilizador é apenas permitido o descarregamento para uso pessoal, pelo que o emprego do(s) título(s) descarregado(s) para outro fim, designadamente comercial, carece de autorização do respetivo autor ou editor da obra.

Na medida em que todas as obras da UC Digitalis se encontram protegidas pelo Código do Direito de Autor e Direitos Conexos e demais legislação aplicável, toda a cópia, parcial ou total, deste documento, nos casos em que é legalmente admitida, deverá conter ou fazer-se acompanhar por este aviso.

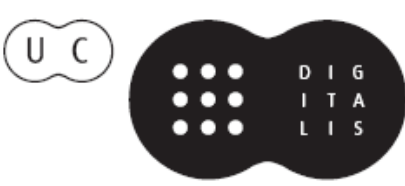




\section{INVESTIGAÇÃO OPERACIONAL EM AÇÃO \\ CASOS DE APLICAÇÃO}

RUI CARVALHO OLIVEIRA JOSÉ SOEIRO FERREIRA (EDITORES)

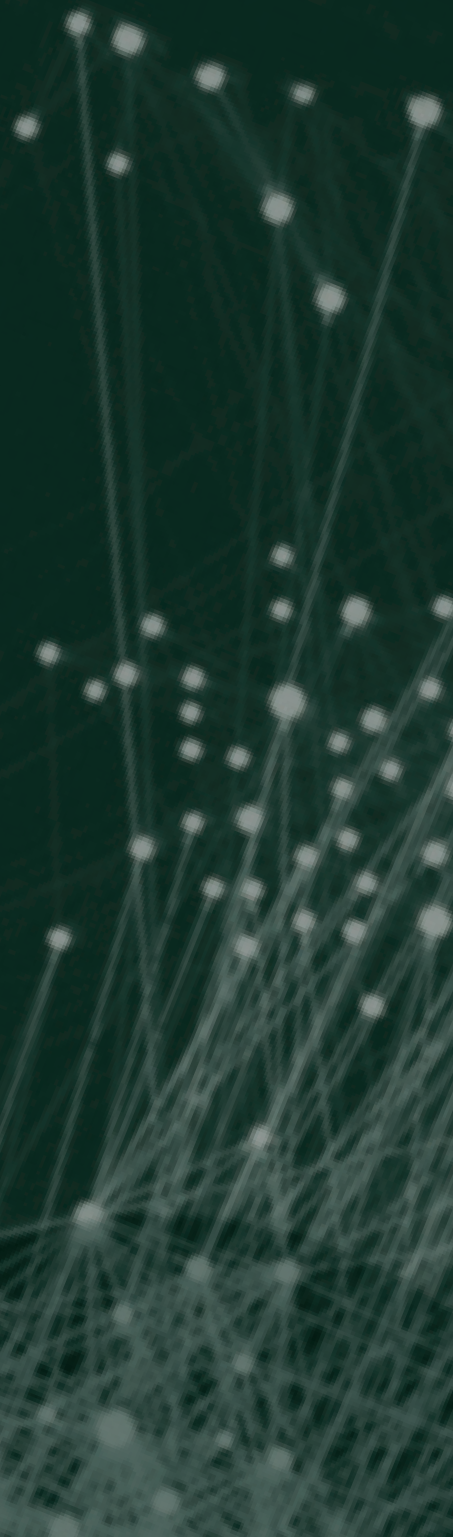




\section{CASO 9}

\section{INTEGRAÇÃO E OTIMIZAÇÃO DE PROCESSOS NA INDÚSTRIA DE Prensados de MAdeira}

João Miranda

Escola Superior de Tecnologia e Gestão do Instituto Politécnico de Portalegre CERENA - Centro de Recursos Naturais e Ambiente, Instituto Superior Técnico jlmiranda@estgp.pt, joaoluismiranda@ist.utl.pt

Ana Seita

Centro de Processos Químicos, Instituto Superior Técnico ana.seita@ist.utl.pt

Cristina Fernandes CERENA - Centro de Recursos Naturais e Ambiente Instituto Superior Técnico, Universidade de Lisboa mc.fernandes@ist.utl.pt

Henrique A. Matos CERENA - Centro de Recursos Naturais e Ambiente Instituto Superior Técnico, Universidade de Lisboa henrimatos@ist.utl.pt

Clemente Pedro Nunes CERENA - Centro de Recursos Naturais e Ambiente Instituto Superior Técnico, Universidade de Lisboa c.pedronunes@ist.utl.pt 


\section{RESUMO}

A integração energética e a produção de utilidades são de vital importância nos processos químicos, em diferentes setores industriais, desde a petroquímica, aos têxteis, à cerâmica, entre outros. Os processos devem estar energeticamente balanceados, e a viabilidade económica da unidade industrial depende da otimização simultânea dos fluxos energéticos e dos fluxos de produção. Este caso de estudo visa melhorar o desempenho económico de unidades industriais de prensados de madeira, situadas em Tomar e na Nazaré, através da análise de diferentes configurações para produzir as utilidades quentes necessárias. Num enquadramento de sustentabilidade energética, as necessidades térmicas devem ser geradas numa fornalha de biomassa que recorre aos resíduos produzidos em diversas operações do processo (casca, aparas de placas e pó). As unidades industriais utilizavam o fuelóleo, como um dos recursos energéticos, em particular durante os meses de inverno. Neste estudo pretende-se avaliar diferentes configurações de um novo sistema energético das unidades industriais que recorram somente à queima de biomassa. Nos processos industriais as utilidades podem ser geradas de forma direta ou indireta, respetivamente, a partir dos gases de combustão ou através de um termofluido intermédio. Assim, os modelos de investigação operacional podem ajudar a decidir qual a melhor configuração para o sistema energético que permita satisfazer as necessidades de utilidades quentes que o processo requer. As alternativas foram comparadas atendendo aos equipamentos selecionados e seus atributos: a potência requerida para a fornalha e o consumo de biomassa, o número de permutadores/geradores de vapor e área total de transferência de calor, assim como a eficiência global do sistema energético. Para apoio à decisão, foi desenvolvido um modelo de Programação Não-Linear Inteira Mista (MINLP) que considera os detalhes operacionais. A introdução de variáveis binárias permitiu modelar a combinatória das diversas alternativas. Foram ainda, consideradas restrições de caráter prático e/ou baseadas na experiência real de unidades industriais desta natureza.

\section{PALAVRAS-CHAVE}

Otimização; Integração de processos; Eficiência energética, Biomassa, Geração de vapor. 


\section{Introdução}

A economia portuguesa possui atualmente uma elevada intensidade energética e uma forte dependência da importação de energia primária. Assim, nos últimos anos, com a subida do preço do petróleo verificou-se uma perda de competitividade das empresas portuguesas. De acordo com um relatório interno da ADENE/DGEG em fevereiro de 2008, a evolução da intensidade energética em Portugal, expressa em termos do consumo de energia final (tep) por unidade de Produto Interno Bruto (em milhão de euros, a preços constantes de 2000) entre 1997 e 2007, divergiu significativamente da média europeia. A intensidade energética nacional, com valores acima dos 140, teve um crescimento desde 1997 a 2005, verificando-se somente um ligeiro decréscimo nos últimos anos. No entanto, na EU27 a intensidade energética teve durante este período um comportamento sempre decrescente e com valores sempre inferiores a 130 (Magueijo e outros, 2010).

Uma estratégia de utilização eficiente de energia, associada ao controlo e redução do consumo de energia para a mesma riqueza criada, é essencial para a competitividade económica de um país, como indica o Livro Verde para a Eficiência Energética (Direcção-Geral da Energia e dos Transportes / Comissão Europeia, 2005). O aumento da eficiência energética requer desenvolvimentos tecnológicos, bem como medidas que regulamentem o consumo energético e as emissões de gases com efeito de estufa e que estimulem em simultâneo a competitividade económica global das empresas portuguesas. Para além disso, os países que assinaram o protocolo de Quioto têm de criar estratégias para mitigar as emissões destes gases, através do uso de energias renováveis. A biomassa é um recurso renovável e neutro em carbono, e tem sido recentemente utilizado para produzir energia e biocombustíveis (Gassner e Marechal, 2009).

De entre as medidas de eficiência energética aplicáveis a um processo industrial, a Integração de Processos (IP) é uma das mais promissoras, podendo contribuir para uma redução de cerca de 1,8\% no consumo energético até 2020 (Magueijo e outros, 2010). Esta metodologia é uma abordagem sistemática, utilizada na conceção e/ou otimização de processos produtivos, com vista a uma adequada articulação intra e interprocessual que 
permita reduzir significativamente os custos de produção, satisfazendo políticas de utilização racional de energia e de matérias-primas, bem como, entre outros, a redução de efluentes e subprodutos e a minimização de emissões gasosas. O aumento do custo do petróleo, bem como as taxas associadas às emissões de $\mathrm{CO}_{2}$, têm motivado estudos de novas alternativas para otimizar os sistemas energéticos na indústria.

Note-se que será necessário proceder a uma constante reavaliação dos diversos fatores económicos, para que um estudo de otimização e integração energética possa ser utilizado para decisões específicas. Numa primeira etapa é necessário identificar e quantificar o consumo de utilidades quentes em cada unidade do processo, bem como as fontes de energia disponíveis. Numa segunda etapa constrói-se uma superestrutura que representa as várias alternativas possíveis de produzir as utilidades quentes desejadas a partir de diferentes recursos energéticos, usando ou não um fluido intermédio para a transferência de calor. A função objetivo é definida em termos dos custos de equipamento, da área total de transferência e do número de equipamentos.

Soršak e outros (2002) dedicaram-se ao estudo e otimização de redes de permutadores de calor de diferentes tipos. Esse artigo descreve a síntese simultânea de redes de permutadores de calor integrados compreendendo diferente tipos de equipamentos de permuta. A superestrutura geral para integração energética de Yee e Grossmann (1990) foi utilizada e adaptada a vários tipos de permutadores de calor.

Drobez e outros (2010) estudaram a integração energética num processo de produção de biogás através de resíduos animais, com base num modelo MINLP. A solução apresentada indica que se o processo e as instalações auxiliares forem integrados energeticamente é possível poupar a quase totalidade das utilidades quentes e cerca de um terço das utilidades frias. Assim, a maior parte da eletricidade e do calor produzido na cogeração pode ser vendido como excedente para as redes de distribuição. Estas propostas podem melhorar o desempenho económico de uma empresa e reduzir significativamente o impacto ambiental, convertendo resíduos prejudiciais ao meio ambiente, orgânicos e de origem animal, em produtos de valor. 
Mais recentemente, Damours e outros (2011) apresentaram um modelo de Programação Linear Inteira Mista (MILP) visando a integração da cadeia de aprovisionamento de produtos florestais e respetivas biorefinarias. Avaliaram também diferentes estratégias de integração (Flisberg e outros, 2011) numa empresa florestal do Chile. Este tipo de modelos surge como ferramenta de apoio à decisão, sendo naquele estudo claramente explicitados os atributos de validade e oportunidade que são cruciais na tomada de decisão.

Revisite-se também o estudo que visava satisfazer a procura crescente de fertilizantes químicos na Índia (Erlenkotter e Manne, 1968), instalando unidades de produção que suprissem tais necessidades. Ora, entre os decisores não se encontraram resistências quanto a diversas aproximações, tendo o estudo decorrido como previsto. Porém, das duas localizações potenciais que foram selecionadas, apenas uma se concretizou e num faseamento mais conservador do que o indicado no estudo.

Atendendo à mais-valia da modelação dos sistemas processuais, apresentam-se, na secção 2, os enquadramentos da integração e otimização de sistemas de energia e duma aplicação na indústria de prensados de madeira. $\mathrm{Na}$ secção 3, descrevem-se as abordagens sequencial e de otimização simultânea à IP. Na secção 4 descreve-se a modelação matemática da superestrutura de integração energética para o caso de estudo. Na secção 5, apresentam-se considerações de caráter tecnológico, aspetos computacionais e comparam-se resultados. Na secção 6, referem-se as principais conclusões e os desenvolvimentos futuros.

\section{Integração de Processos numa unidade de prensados de madeira}

\subsection{A Integração Energética de Processos em Portugal}

A Integração Energética de Processos pode a um nível mais elevado recorrer a componentes processuais que ajudem a aumentar a eficiência global do Processo, fazendo a integração global com todo o sistema de utilidades. A produção de energia a partir de fontes renováveis adquiriu especial importância no quadro da política energética da UE em virtude do

agravamento da situação de forte dependência energética em relação ao petróleo pelo recente aumento do seu preço. O uso de biomassa florestal para 
produção de energia elétrica constitui uma alternativa interessante à utilização de combustíveis de origem fóssil, de que Portugal é importador, e deve portanto ser explorada de forma sustentada e sempre que possível integrada numa estratégia adequada de cogeração, onde o aproveitamento da energia térmica permite valores de eficiência superiores a $85 \%$.

A aplicação das Metodologias de Integração de Processos tem um enquadramento português através do Grupo Nacional para a Integração de Processos (GNIP, http://gnip.ist.utl.pt/ ). Este grupo é um consórcio de instituições, empresas e universidades constituído em 7 de abril de 1995 com o objetivo genérico de divulgar e promover as metodologias de Integração de Processos em Portugal. Este consórcio manteve o apoio necessário à participação portuguesa no Acordo Internacional para a Integração de Processos no âmbito da AIE-Agência Internacional Energia (1995-2005). O GNIP participou ainda num Anexo sob o título "Energy Systems Integration Between Society and Industry Including Cogeneration Systems and Power Plants», que integrou ainda a Finlândia, Canadá e Suécia.

Atualmente o GNIP participa no Acordo da AIE denominado IETS-Industrial Energy-related Tecnology \& Systems (IETS). Este acordo engloba vários anexos: Sistemas de Separação Energeticamente Eficientes (Anexo IX); Secagem Energeticamente Eficiente (Anexo X); Biorefinarias baseadas na Indústria (Anexo XI); Tecnologia de Membranas para a Separação Energeticamente Eficiente de Hidrocarbonetos (Anexo XII); Bombas de Calor Industriais (Anexo XIII) entre outros. Outra informação adicional pode ser obtida em http://www.iea-industry.org/. O GNIP tem nos últimos anos participado em alguns projetos de divulgação e aplicação das metodologias de IP. Diferentes empresas portuguesas foram já alvo de aplicação das metodologias de IP, podendo ser apontados os estudos no setor da Química de Base, Adubos, Têxtil, Celulose, Petroquímica e Madeira.

Nas últimas décadas, além dos trabalhos de investigação desenvolvidos pelas universidades, também os trabalhos de aplicação em unidades industriais ilustram a importância da obtenção de processos integrados e otimizados. O objetivo destes estudos é, não só definir a própria configuração/estrutura 
processual, como também calcular os valores das variáveis importantes do processo.

Qualquer alteração de um equipamento, ou de caraterísticas de uma corrente de processo (ex: temperatura de vapor, caudal, composição), propagase ao longo de todo o sistema em termos de operação e rentabilidade. Assim, a análise e compreensão global de todo o processo deverá ser um requisito mínimo para uma atuação de sucesso no incremento da competitividade na Indústria de Processos.

\subsection{O sistema energético de uma unidade de prensados de madeira}

Num processo de produção de prensados de madeira, as fibras são obtidas por processos termo-mecânicos, a partir de toros de madeira destroçados que são previamente aquecidos com vapor antes do desfibramento. Algumas unidades requerem uma atmosfera húmida para a produção dos painéis, que posteriormente são sujeitos a uma prensa e enviados para as câmaras de estabilização para absorção da humidade. Durante a compressão do painel, produz-se um licor negro que é enviado para uma unidade de evaporação. Noutras unidades, caso dos painéis de MDF, Median Density Fiberboard, após o desfibrador são adicionadas resinas e corantes. A fibra é seca, em contra corrente com ar quente, passando posteriormente por um pendistor, e por uma formadora de manta. Os painéis são produzidos a partir da compressão a frio e a quente da manta de fibras, tal como se apresenta no diagrama da Figura 1.

Assim, tanto no caso dos prensados de madeira como no caso da produção de MDF, verifica-se que estas fábricas têm um elevado consumo de utilidades quentes, maioritariamente vapor, produzido a partir da biomassa e do fuelóleo. Durante o inverno quando escasseia a biomassa e esta é mais húmida, o fuelóleo era usado para garantir o caudal de vapor necessário para satisfazer as necessidades do processo. Consequentemente, o custo final destes derivados da madeira é amplamente dependente da eficiência e dos combustíveis utilizados para produção de energia térmica. 


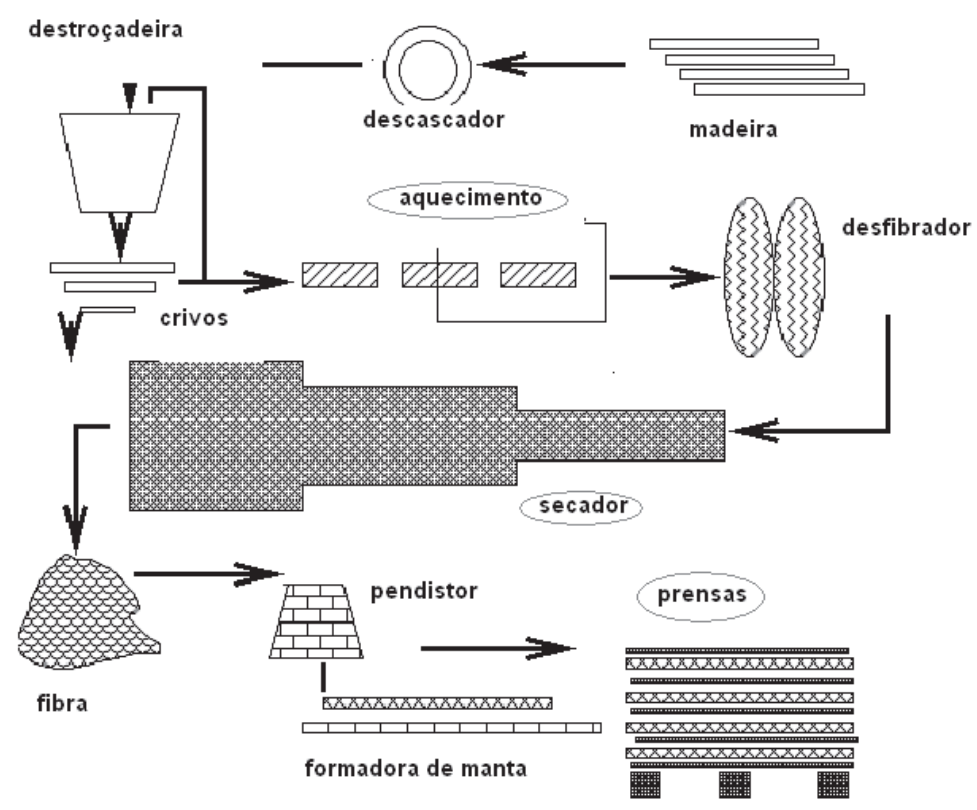

Figura 1 - Diagrama simplificado do processo de formação de MDF

Na Figura 2 apresenta-se o diagrama que descreve as necessidades de utilidades quentes de uma unidade de cartões prensados de madeira. Neste diagrama, o vapor é gerado em duas caldeiras que utilizam os gases provenientes da queima de biomassa e/ou fuelóleo numa fornalha de grelha. O forno queima serradura, aparas de cartão duro, casca e resíduos produzidos no processo. A caldeira principal gera vapor de 21 bar, que é usado nas prensas e nas câmaras térmicas, enquanto a outra caldeira produz vapor a 11 bar para o desfibramento da madeira destroçada, para as câmaras de humidificação e para a unidade de evaporação (a 2 bar). Note-se que embora os processos industriais em Tomar e Nazaré sejam diferentes, os sistemas energéticos eram inicialmente similares e a Figura 2 constitui uma boa aproximação a ambos os sistemas.

Neste estudo, pretende-se substituir os sistemas de produção de utilidades quentes da unidade de prensados e da unidade de MDF, definindo-se o tipo de equipamento, número de unidades de permuta e respetiva dimensão (área de 
transferência), bem como selecionar a melhor configuração estrutural para a recuperação energética dos gases de combustão, de forma a garantir que:

- $\quad$ se utilize somente biomassa;

- em todas as alternativas propostas, apenas é necessário uma fornalha para gerar os gases de combustão que permitem posteriormente produzir as utilidades necessárias ao processo. Esta nova fornalha inclui uma grelha móvel capaz de queimar exclusivamente biomassa com humidade elevada bem como o pó gerado no processo.

- $\quad$ entre as várias alternativas o vapor pode ser gerado diretamente a partir dos gases de combustão ou através de fluido intermédio (termofluido).

- o balanço deve considerar aspetos económicos, como os custos de investimento em equipamentos de permuta energética, custos de utilidades quentes e frias.

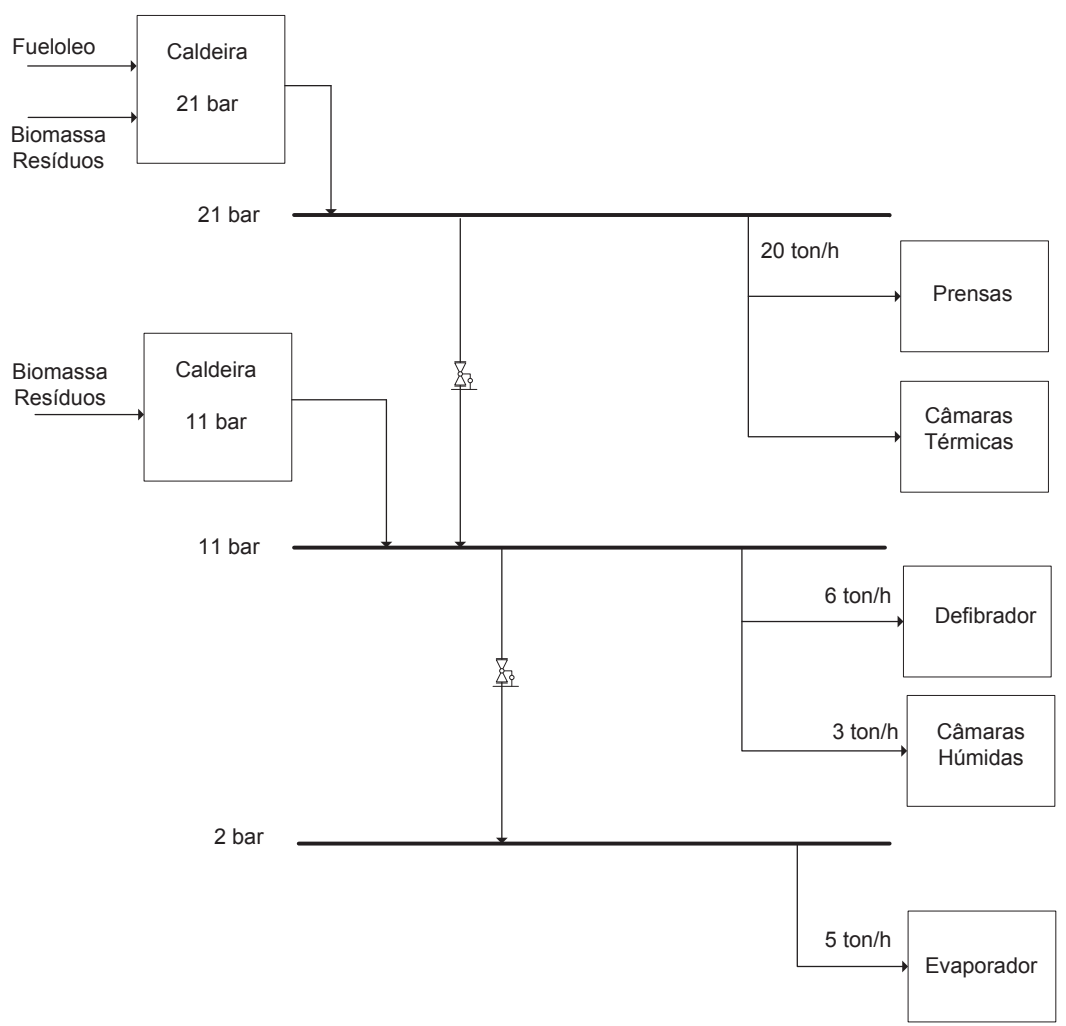

Figura 2 - Rede inicial das utilidades quentes (vapor) numa unidade de cartões prensados de madeira. 
Na secção seguinte apresentam-se as abordagens que permitem a escolha da melhor alternativa económica, sendo o caso em estudo um problema típico de IP onde se pretende configurar a melhor rede de permutadores de calor.

\section{Abordagens à modelação para a Integração de Processos}

Nesta secção, visam-se as abordagens à modelação para a IP de forma a melhorar a sua contextualização, bem como para evidenciar as fortes ligações entre os métodos da Engenharia de Sistemas de Processos (Process Systems Engineering) e da Investigação Operacional. Nomeadamente, apresenta-se a analogia com o problema de Transporte e o seu caso especial de Transexpedição, ilustrando-se com um exemplo numérico simples. Note-se que os intervalos de temperatura e conteúdos energéticos da referida analogia podem ser utilizados na construção da superestrutura da rede de permutadores, tal como se descreve posteriormente na secção 4 .

\subsection{A abordagem sequencial e por otimização simultânea}

A síntese de redes de permutadores de calor (heat exchanger network synthesis, HENS) é um problema bem conhecido da Engenharia de Sistemas de Processos (Process Systems Engineering), estando bem disseminadas as abordagens sequenciais que se baseiam no método do ponto de estrangulamento (pinch point method), como mostraram Linnhof e outros (1982). Nesta abordagem sequencial, minimiza-se o consumo de utilidades energéticas, em seguida minimiza-se o número de permutadores requeridos, e finalmente minimiza-se o custo total de equipamentos e energia.

Através deste tipo de abordagem sequencial, Seita e outros (2009) desenvolveram um estudo de integração energética numa unidade de produção de prensados de madeira de MDF. Após uma análise global da unidade industrial, aplicou-se o método do ponto de estrangulamento para estabelecer a rede de recuperação máxima (Maximum Energy Recovery, MER).

O método pinch funciona como uma primeira abordagem para a análise de integração energética entre as várias correntes de um processo. Esta metodologia permite determinar entre que correntes poderá ser realizada a integração, mas não permite a discussão e a avaliação económica dos vários 
cenários estruturais alternativos, nem a discussão da sua viabilidade técnicaeconómica. Assim, a abordagem sequencial com base no método pinch pode conduzir a desvios face ao ótimo global uma vez que a qualidade da solução em cada fase depende da qualidade da solução obtida numa fase anterior. Então, a otimização simultânea do objetivo económico, balanceando o custo de equipamentos e o custo de utilidades, revela-se necessária. Deste modo, podem conjugar-se os vários aspetos do problema HENS, integrar-se de forma efetiva as interações entre os diversos subproblemas, formular custos fixos e custos variáveis, bem como promover a robustez do modelo e da solução.

Miranda e Casquilho (2007) apresentaram um modelo robusto de HENS, com variáveis binárias associadas à seleção de equipamentos e com cenários probabilísticos para emular a incerteza. O enquadramento em Programação Estocástica em Duas Fases (Two-stage Stochastic Programming) visava: i) a seleção dos equipamentos na primeira fase, por especificação das variáveis binárias $\{0,1\}$; ii) após concretização dos cenários, a minimização dos custos de recurso em segunda fase visava a definição das variáveis contínuas das utilidades energéticas. No entanto, a resolução de tal modelo revelou grandes dificuldades, inerentes à complexidade do problema em questão.

A classificação de complexidade computacional de vários problemas de HENS foi estabelecida por Furman e Sahinidis (2001): enquanto os modelos de Programação Linear correspondiam a problemas da classe P, os modelos MILP por eles estudados correspondem a problemas NP-difíceis em sentido forte (NP-hard in strong sense). Tais estudos de complexidade computacional permitem também perspetivar esquemas de resolução que possam ser úteis perante a dificuldade de grandes instâncias destes problemas. A Tabela 1 apresenta sinoticamente algumas referências de interesse e, quando possível, a classificação de complexidade computacional dos problemas tratados.

\subsection{A analogia com o problema de Transporte}

Ora, na formulação de modelos são usuais as abordagens construtiva e por «template». A abordagem construtiva é mais fundamental, sendo comuns os procedimentos de caráter geral que visam a definição do objetivo a otimizar, a definição das variáveis de decisão e a especificação das restrições funcionais. A 
abordagem por "template» utiliza modelos existentes que possam ser ajustados de forma suficiente à situação real. Além disso, a situação real pode exigir a combinação de formulações de diferentes tipos de problemas, quando não é possível que um só modelo represente os aspetos importantes da situação.

Tabela 1 - Sinopse de referências no âmbito da Integração de Processos

\begin{tabular}{|c|c|c|}
\hline Ano & Autores & Assunto \\
\hline 1982 & Linnhoff e outros & $\begin{array}{l}\text { Análise termodinâmica a redes de integração } \\
\text { energética }\end{array}$ \\
\hline 1983 & Cerda e Westerberg & $\begin{array}{l}\text { Modelação dos fluxos caloríficos em rede de } \\
\text { transportes (transportation); problema NP- } \\
\text { difícil em sentido forte para modelo MILP } \\
\text { de permutas (matches) }\end{array}$ \\
\hline 1983 & Papoulias e Grossmann & $\begin{array}{l}\text { Modelação dos fluxos em rede de transexpedição } \\
\text { (transshipment); problema } \mathrm{P}\end{array}$ \\
\hline 1986 & Saboo e outros & $\begin{array}{l}\text { Implementação computacional dos modelos de } \\
\text { transshipment }\end{array}$ \\
\hline 1990 & Yee e outros & $\begin{array}{l}\text { Otimização simultânea do sistema processual e da } \\
\text { rede energética; problema NP-difícil em } \\
\text { sentido forte }\end{array}$ \\
\hline 1994 & Daichendt e Grossmann & $\begin{array}{l}\text { Avaliação preliminar de alternativas utilizando } \\
\text { modelos agregados }\end{array}$ \\
\hline 2001 & Furman e Sahinidis & $\begin{array}{l}\text { Estudo de complexidade computacional de } \\
\text { problemas de HENS }\end{array}$ \\
\hline 2008 & Relvas e outros & $\begin{array}{l}\text { Aplicação do método pinch a redes de } \\
\text { transferência de massa }\end{array}$ \\
\hline 2011 & Martín e Grossmann & $\begin{array}{l}\text { Otimização energética na produção de hidrogénio } \\
\text { a partir de biomassa lenhocelulósica }\end{array}$ \\
\hline
\end{tabular}

Esta abordagem por «template» permite agilizar a modelação do problema, existindo uma tipificação de problemas de otimização como sejam o conhecido problema de Transporte (Transportation) e os seus casos especiais (Transshipment, Production Allocation, Assignment). Por exemplo, Cerda e Westerberger (1983) recorrem a formulações de Transporte para minimização dos consumos energéticos em redes de permutadores, considerando: as correntes quentes como origens e os respetivos fluxos energéticos como disponibilidades; as correntes frias como destinos, com as correspondentes necessidades energéticas. 
Tabela 2 Dados para analogia de Transporte

\begin{tabular}{ccccc}
\hline Corrente & FCp $(\mathrm{MW} / \mathrm{oC})$ & Tin(으) & Tout(ㅇ) & Q= - FCp (Tout-Tin) \\
\hline H1 & 1,5 & 390 & 190 & 300 \\
H2 & 1 & 290 & 190 & 100 \\
C1 & 2 & 25 & 125 & -200 \\
C2 & 1 & 125 & 325 & -200 \\
\hline
\end{tabular}

Exemplifica-se a analogia com duas correntes quentes (H1 e H2) e duas correntes frias ( $C 1$ e $C 2$ ). Na Tabela 2 apresentam-se os respeitantes conteúdos energéticos (FCp), temperaturas de entrada (Tin) e de saída (Tout), bem como as quantidades energéticas em permuta $(Q)$. Então, obtém-se o usual grafo bipartido do problema de Transporte (Figura 3).

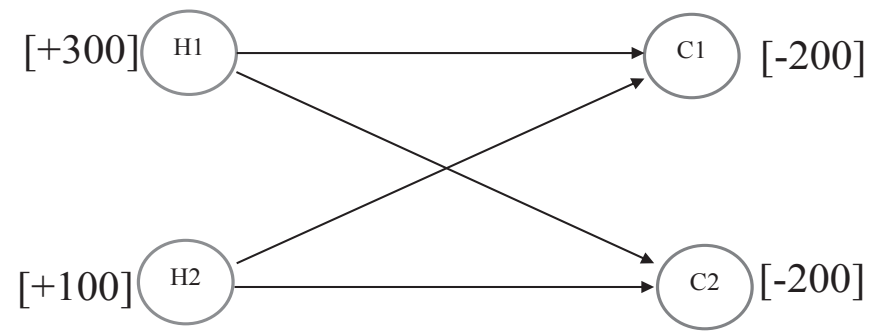

Figura 3 - Ilustração da analogia com o problema de Transporte

A generalização ao problema de Transexpedição (Transshipment) desenvolve-se considerando os intervalos de temperatura como entrepostos.

Tabela 3 - Conteúdos energéticos e intervalos de temperatura

\begin{tabular}{ccccc}
\hline $\begin{array}{c}\text { Intervalos } \\
\left.\text { (em }{ }^{\circ} \mathbf{C}\right)\end{array}$ & H1 & H2 & C1 & C2 \\
\hline I - de 390 a 325 & 97,5 & & \\
II - de 325 a 290 & 52,5 & & 35 \\
III -de 290 a 190 & 150 & 100 & 100 \\
IV -de 190 a 125 & & & 65 \\
V - de 25 a 125 & & $\mathbf{1 0 0}$ & $\mathbf{2 0 0}$ & $\mathbf{2 0 0}$ \\
\hline SOMA & $\mathbf{3 0 0}$ & & & \\
\hline
\end{tabular}


Na Tabela 3 apresentam-se os valores dos conteúdos energéticos em cada intervalo de temperaturas, para os valores do exemplo anterior. Por razões de simplicidade mas que não afetam o objeto deste exemplo ilustrativo, note-se que não foram consideradas as diferenças de temperatura entre as correntes quentes e frias. Obviamente que sem tal força motriz não haveria transferência de energia térmica!

Os valores em excesso em cada intervalo de temperatura são transferidos para o intervalo de temperatura imediatamente inferior, definindo assim os fluxos residuais de energia. Tais fluxos residuais são apresentados entre parêntesis na Figura 4, ilustrando a designada "cascata de calor» e que corresponde à estrutura de fluxos térmicos segundo a formulação em Transexpedição.

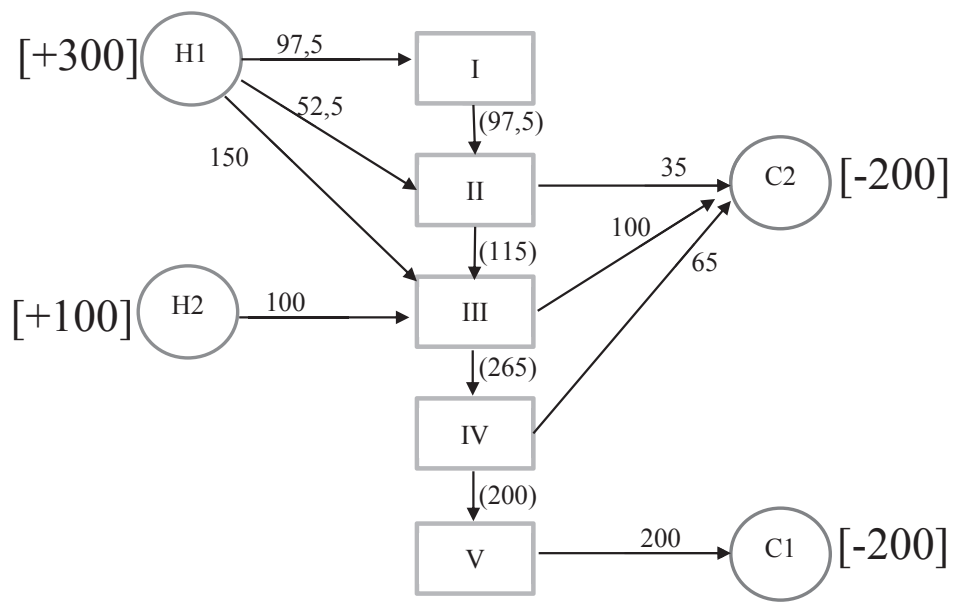

Figura 4 - Ilustração de superestrutura por analogia com o problema de Transexpedição

Este simples exemplo ilustra um caso em que as correntes são satisfeitas de forma interna sem necessidade de consumo externo de utilidades. Atente-se também que as temperaturas e os conteúdos energéticos das correntes são aqui parâmetros do problema, e não variáveis a otimizar.

\section{Modelação do caso de estudo}

Apresenta-se na Figura 5 o esquema da superestrutura desenvolvida para o caso de estudo industrial onde se considera queima de biomassa como 
combustível e a respetiva produção de gases de combustão (a encarnado). Estes gases serão posteriormente aproveitados para produzir as utilidades quentes necessárias ao processo (vapor de alta, média e baixa pressão; a negro), diretamente e/ou através de um termofluido intermédio (a verde).

Nesta superestrutura conjugam-se as múltiplas e diversas alternativas a considerar em termos de equipamentos, permutadores, correntes diversas (gases de combustão, termofluidos quentes e frios, vapores a diferentes pressões), visando-se o aproveitamento energético dos gases de combustão produzidos na fornalha. A seleção da melhor configuração recorre ao desenvolvimento de um modelo de programação matemática que considere simultaneamente os fatores tecnológicos e os económicos.

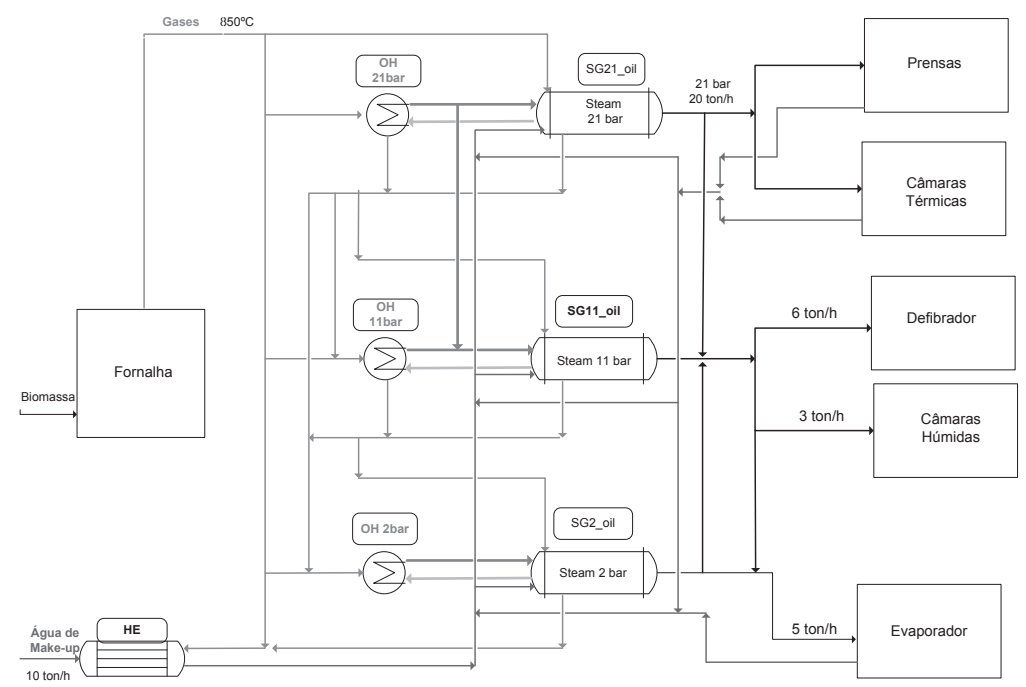

Figura 5 - Superestrutura para aproveitamento energético de gases de combustão

O modelo robusto de Miranda e Casquilho (2007) foi ajustado ao contexto deste caso de estudo. Tal modelo usa como "template» a superestrutura geral para integração energética de Yee e outros (1990), a qual considera simultaneamente os fatores de projeto: consumo de utilidades, número de permutadores, área total para transferência de energia térmica. Tal «template» 
encontra-se disponível no ambiente GAMS (General Algebraic Modeling System) com a designação «SYNHEAT».

A superestrutura geral para integração energética (Yee e outros, 1990) apresenta as diversas possibilidades de permuta entre as correntes, mas não exige a definição do ponto de estrangulamento ou a partição em subredes. Considera-se o seguinte procedimento:

1. Definir o número de estágios («entrepostos»), selecionando-se o valor máximo entre o número de correntes frias e de correntes quentes, pois o número ótimo de permutadores não é usualmente superior ao número de correntes; numa abordagem mais rigorosa, deve considerarse igual número de estágios e de intervalos de temperatura (Daichendt e Grossmann, 1994);

2. Em cada estágio, a corrente é dividida e direcionada para um possível permutador entre cada corrente quente e cada corrente fria; as correntes de saída dos permutadores são misturadas isotermicamente, definindo as correntes de entrada para o estágio seguinte;

3. As temperaturas à saída de cada estágio são tratadas como variáveis a otimizar, não se requerendo a pré-definição dos intervalos de temperatura.

Essa superestrutura geral contém algumas limitações. Não supõe a ocorrência de correntes de passagem (by-pass), exceto para situações específicas, como por exemplo:

- quando interessar manter uma força motriz elevada, ou

- $\quad$ onde seja necessário garantir a observância do $\Delta$ Tmin entre as correntes em permuta, para o que seria necessário diminuir o fluxo mássico da corrente fria através de um by-pass (geralmente, a adição de uma corrente deste tipo poderá beneficiar a rede em termos de números de unidades, mas com um aumento das áreas de transferência).

A superestrutura geral para integração energética é incorporada frequentemente em problemas mais complexos, conduzindo a uma formulação não linear (NLP) ou mesmo a uma formulação MINLP se se introduzirem variáveis binárias, como se apresenta em seguida. 
O balanço energético global a cada corrente quente $i$ considera as permutas com as correntes frias $j$ ao longo dos diversos estágios $k$, $Q_{i j k}$, bem como a necessidade de se recorrer a uma corrente para arrefecimento, onde se permuta a quantidade, $Q c u_{i}$ :

h.1

$$
F C p_{i}\left(T I N_{i}-T O U T_{i}\right)=\sum_{k \in K} \sum_{j \in C} Q_{i j k}+Q c u_{i} \quad, \quad \forall i
$$

No primeiro membro define-se o conteúdo entálpico da corrente quente $i$, $F C p_{i}$, que no âmbito da otimização simultânea é tratado como variável, tal como as temperaturas de entrada TIN e saída TOUT das correntes. Assim, obtém-se um grupo de equações não lineares, mas caso sejam definidos ou estimados os valores daqueles fluxos, as equações descritas nestas restrições reduzem-se a relações lineares.

De igual modo, tem-se o balanço energético para cada uma das correntes frias onde poderá ter de se recorrer a utilidades para aquecimento, $Q h u_{j}$ :

$$
\text { h.2 } F C p_{j}\left(\operatorname{TOUT}_{j}-\text { TIN }_{j}\right)=\sum_{k \in K} \sum_{i \in H} Q_{i j k}+Q h u_{j}, \forall j
$$

O balanço energético em cada estágio $k$, tanto para as correntes quentes como para as correntes frias, origina também restrições não-lineares no primeiro membro:

h.3

$$
\left\{\begin{array}{l}
F C p_{i}\left(T_{i k}-T_{i, k+1}\right)=\sum_{j \in C} Q_{i j k}, \forall i, k \\
F C p_{j}\left(T_{j k}-T_{j, k+1}\right)=\sum_{i \in H} Q_{i j k}, \forall j, k
\end{array}\right.
$$

As temperaturas de entrada das correntes quentes e frias, respetivamente, definem as temperaturas no primeiro e último estágio na superestrutura:

h.4

$$
\left\{\begin{array}{l}
T I N_{i}=T_{i 1}, \quad \forall i \\
T I N_{j}=T_{j, K+1}, \quad \forall j
\end{array}\right.
$$

Presume-se um perfil monotonamente decrescente das temperaturas ao longo dos diversos estágios:

h.5

$$
\left\{\begin{array}{l}
T_{i k} \geq T_{i, k+1}, \quad \forall i, k \\
T_{j k} \geq T_{j, k+1}, \quad \forall j, k
\end{array}\right.
$$


Assume-se também a existência de folgas nas temperaturas à saída da superestrutura, as quais servem posteriormente para definir os requisitos de utilidades:

h.6

$$
\left\{\begin{array}{l}
\text { TOUT }_{i} \leq T_{i, K+1}, \quad \forall i \\
\text { TOUT }_{j} \geq T_{j 1}, \quad \forall j
\end{array}\right.
$$

O consumo de utilidades, quente $Q h u_{j}$ e fria $Q c u_{i}$, é assim determinado pela diferença entre as temperaturas à saída da superestrutura e as temperaturas requeridas pelas correntes de processo:

h.7

$$
\left\{\begin{array}{l}
F C p_{i}\left(T_{i, K+1}-\mathrm{TOUT}_{i}\right)=Q \mathrm{Qcu_{i }}, \quad \forall i \\
F C p_{j}\left(\mathrm{TOUT}_{j}-T_{j 1}\right)=Q h u_{j}, \quad \forall j
\end{array}\right.
$$

Repare-se que no exemplo ilustrativo da secção 3.2 os consumos de utilidades são nulos $\left(Q h u_{j}=Q c u_{i}=0\right)$ : o problema típico de Transporte requer como condição necessária que a soma das disponibilidades nas origens iguale a soma das procuras nos destinos (e a soma de todos os fluxos). Então, as permutas energéticas, $Q_{i j k}$, entre correntes quentes $i$ e frias $j$ ao longo dos estágios $k$ (intervalos de temperatura) podem ser lidas diretamente da Tabela 3.

Assim, a corrente quente H1 será a origem de 300 MW que serão distribuídos pelos três primeiros estágios (entrepostos), concretamente, $Q_{1 j 1}=$ 97,5 MW para o primeiro estágio, $Q_{1 j 2}=52,5 \mathrm{MW}$ para o segundo e os restantes $Q_{1 j 3}=150 \mathrm{MW}$ para o terceiro. E os valores das respetivas permutas para o quarto e quinto estágio são nulos $\left(Q_{1 j 4}=Q_{1 j 5}=0\right)$.

As permutas energéticas referentes às restantes correntes, $H 2, C 1$ e $C 2$, podem obter-se de forma similar. Atente-se que para favorecer a leitura, na definição dos estágios deste exemplo ilustrativo não foram consideradas as diferenças mínimas de temperatura ( $\Delta$ Tmin) que devem existir para promover a transferência de energia térmica entre correntes quentes e frias!

A área de cada permutador é definida através da relação habitual, envolvendo a carga energética em permuta $Q_{i j}$, o coeficiente de transferência global $U_{i j}$, bem como a diferença de temperaturas logarítmica média (log mean temperature difference) $L M T D_{i j}$ : 
h.8

$$
A_{i j}=\frac{Q_{i j}}{U_{i j} L M T D_{i j}}
$$

onde

h.9

$$
L M T D_{i j}=\frac{\left.d T\right|_{2}-\left.d T\right|_{1}}{\ln \left(\left.d T\right|_{2}\right)-\ln \left(\left.d T\right|_{1}\right)}
$$

Considerando a otimização simultânea do fluxograma e da rede de integração energética, a introdução de variáveis binárias possibilita a especificação das unidades de permuta, donde se pode estabelecer um conjunto de restrições de caráter lógico sobre as demais variáveis de decisão.

As trocas caloríficas entre as correntes quentes e frias, $Q_{i j k}$, e as utilidades de interesse, $Q c u_{i}$ e $Q h u_{j}$, são tratadas como variáveis semicontínuas (ou se anulam, ou encontram-se delimitadas superiormente por $Q^{U P D}$ ), conforme as restrições formuladas com as variáveis binárias $y_{i j k}, y c u_{i}, y b u_{j}$ :

h.10

$$
\begin{cases}Q_{i j k} \leq Q^{U p p} \cdot y_{i j k}, & \forall i, j, k \\ Q c u_{i} \leq Q^{U p p} \cdot y c u_{i}, & \forall i \\ Q h u_{j} \leq Q^{U p p} \cdot y h u_{j} & , \quad \forall j\end{cases}
$$

Para cada um dos diferentes tipos de permuta energética, a determinação da força motriz $d T$ para a transferência energética também utiliza relações de índole lógica, estabelecendo-se (até por necessidade numérica!) uma abordagem de diferença mínima de temperaturas, $\Delta T$ Tin:

h.11

$$
\left\{\begin{array}{l}
d T_{i j k} \leq T_{i k}-T_{j k}+d T^{U p p}\left(1-y_{i j k}\right) \\
d T_{i j, k+1} \leq T_{i, k+1}-T_{j, k+1}+d T^{U p p}\left(1-y_{i j k}\right)
\end{array}, \quad \forall i, j, k\right.
$$

h.12

$$
\left\{\begin{array}{l}
\left.d T c u_{i}\right|_{1} \leq T_{i, K+1}-\operatorname{TOUT}_{c u}+d T^{U p p}\left(1-y c u_{i}\right) \\
\left.d T c u_{i}\right|_{2} \leq T O U T_{i}-\operatorname{TIN}_{c u}+d T^{U p p}\left(1-y c u_{i}\right)
\end{array}, \quad \forall i\right.
$$

h.13

$$
\left\{\begin{array}{l}
\left.d T h u_{j}\right|_{1} \leq \operatorname{TOUT}_{h u}-T_{j 1}+d T^{U p p}\left(1-y h u_{j}\right) \\
\left.d T h u_{j}\right|_{2} \leq \operatorname{TIN}_{h u}-\operatorname{TOUT}_{j}+d T^{U p p}\left(1-y h u_{j}\right)
\end{array}, \quad \forall j\right.
$$

h.14

$$
d T_{i j k}, d T c u_{i}, d T h u_{j} \geq \Delta \operatorname{Tmin}, \quad \forall i, j, k
$$


As temperaturas das correntes de saída das utilidades são parâmetros do problema, mas as diferenças de temperatura $d T$ são variáveis de decisão. No caso específico da aplicação às utilidades, os índices 1 e 2 introduzidos referem as diferenças de temperaturas em cada uma das extremidades dos permutadores, ou seja, à entrada (1) e à saída (2) dos permutadores supostamente em contracorrente.

A função objetivo prevê a minimização dos custos das utilidades e dos custos para investimento, privilegiando também economias de escala através do expoente fracionário que valoriza as áreas de transferência. Relembra-se que as áreas de transferência dependem das quantidades energéticas permutadas, dos coeficientes de transferência globais, da diferença logarítmica média das temperaturas (LMTD), em conformidade com as equações h.8 e h.9. Com a introdução de variáveis binárias, também se consideram os custos fixos dos equipamentos. Assim, a função objetivo é da forma:

h.15

$$
[\min ] z=C c u \sum_{i \in H} Q c u_{i}+C h u \sum_{j \in C} Q h u_{j}
$$

$$
\begin{aligned}
& +C V_{i j} \sum_{i \in H} \sum_{j \in C} \sum_{k \in K}\left[A_{i j k}\right]^{\beta_{i j}}+C V_{c u, i} \sum_{i \in H}\left[A c u_{i}\right]^{\beta_{c u, i}}+C V_{h u, j} \sum_{j \in C}\left[A h u_{j}\right]^{\beta_{h u, j}} \\
& +\sum_{i \in H} \sum_{j \in C} \sum_{k \in K} C F_{i j} y_{i j k}+\sum_{i \in H} C F_{c u, i} y c u_{i}+\sum_{j \in C} C F_{h u, j} y h u_{j}
\end{aligned}
$$

Então, agrupando as relações h.1-h.15 obtém-se no grupo de relações h.16 (a-d) um modelo não linear com variáveis inteiras (binárias), o modelo minlp_simsup. Tal modelo avalia os custos de utilidades e os custos de investimento, de natureza fixa ou variável, e em simultâneo define a rede ótima de permutadores de calor a partir da superestrutura:

\section{Modelo minlp_simsup:}

h.16-a

$$
\begin{aligned}
{[\min ] z=} & C c u \sum_{i \in H} Q c u_{i}+C h u \sum_{j \in C} Q h u_{j} \\
& +C V_{i j} \sum_{i \in H} \sum_{j \in C} \sum_{k \in K}\left[A_{i j k}\right]^{\beta_{i j}}+C V_{c u, i} \sum_{i \in H}\left[A c u_{i}\right]^{\beta_{c u, i}}+C V_{h u, j} \sum_{j \in C}\left[A h u_{j}\right]^{\beta_{h u, j}} \\
& +\sum_{i \in H} \sum_{j \in C} \sum_{k \in K} C F_{i j} y_{i j k}+\sum_{i \in H} C F_{c u, i} y c u_{i}+\sum_{j \in C} C F_{h u, j} y h u_{j}
\end{aligned}
$$

sujeito a, 


$$
Q c u_{i}, Q h u_{j}, Q_{i j k}, A c u_{i}, A h u_{j}, A_{i j k}, T_{i k}, T_{j k} \geq 0, \forall i, j, k
$$

h.16-c

$$
\begin{gathered}
F C p_{i}, F C p_{j}, \operatorname{TIN}_{i}, \operatorname{TOUT}_{i}, \operatorname{TIN}_{j}, \operatorname{TOUT}_{j} \geq 0, \forall i, j \\
y c u_{i}, y h u_{j}, y_{i j k} \in\{0,1\}, \forall i, j, k
\end{gathered}
$$

h.16-d

Embora os fluxos e temperaturas das correntes de processo sejam considerados parâmetros nas analogias de Transporte e Transexpedição, tais fluxos e temperaturas são variáveis a determinar no âmbito da otimização simultânea de todo o sistema energético, pelo que o modelo se torna nãolinear. Repare-se que:

- Caso não se incorporem na função objetivo h.15 os custos exponenciais referentes às áreas de transferência, obtém-se um submodelo MILP.

- Caso não se considerem as parcelas referentes às variáveis binárias em h.15, bem como se especifiquem as relações de índole lógica h.10h.14, obter-se-ia uma formulação NLP. Esse submodelo de NLP seria não-convexo, pois várias restrições apresentam termos bilineares. A configuração ótima da rede de permutadores viria implicitamente da leitura dos valores não-nulos para as áreas, bem como dos valores para as transferências energéticas.

- Se for definido um nível específico de recuperação energética, através da fixação do nível de utilidades requeridas pela rede, o problema reduz-se à minimização da área de transferência.

- Caso ocorra a fixação dos valores dos fluxos FCp, obtém-se um modelo onde ocorrem apenas restrições lineares, revelando-se as nãolinearidades somente na função objetivo. A resolução é mais simples, pois não só o espaço de procura das soluções possíveis será convexo, como a dimensionalidade do problema será menor.

Estas alterações, generalizações ou simplificações, são importantes para a resolução de problemas MINLP de grande dimensão, pois permitem obter resultados parciais e configurações de boa qualidade para a rede de integração energética. Embora tais alterações possam conduzir a soluções subótimas, promovem a análise, a comparação e delimitam a procura de configurações melhores. Caso tal procura seja sistemática e satisfaça os procedimentos de 
decomposição hierárquica de Daichendt e Grossmann (1997), para além de se evitar a resolução de um problema MINLP de grande dimensão, também a otimalidade duma configuração pode ser assegurada através dum esquema com caraterísticas similares ao branch-and-bound.

Considerando o problema detalhado para a síntese do subsistema de integração energética, observa-se a não-convexidade do modelo MINLP proposto, o que agrava ainda mais a dificuldade inerente aos modelos MINLP de grande dimensão. Têm sido desenvolvidos esforços para melhorar a eficiência dos esquemas de resolução, como sejam a introdução de modelos agregados e convexos, ou a incorporação de aspetos de índole termodinâmica, visando reduzir as dificuldades na fase inicial do cálculo, mas tendo o cuidado de preservar a otimalidade da solução.

\section{Aspetos de Otimização e análise de resultados}

\subsection{Considerações de caráter tecnológico exigidas na implementação em} ambiente real

$\mathrm{Na}$ formulação do problema foi necessário ter em consideração algumas aproximações e garantir alguns parâmetros tecnológicos de funcionamento:

1) A diferença de temperatura mínima ( $\Delta \mathrm{Tmin}$ ) entre as correntes quentes e as correntes frias é de $30^{\circ} \mathrm{C}$, exceto no primeiro permutador de calor que usa os gases provenientes da fornalha onde o $\Delta T$ Tin é de $90^{\circ} \mathrm{C}$.

2) A variação de temperatura do termofluido nos permutadores é de $40^{\circ} \mathrm{C}$.

3) $\mathrm{O}$ termofluido para produção de vapor a 21 bar funciona de $280^{\circ} \mathrm{C}$ a $240^{\circ} \mathrm{C}$, enquanto que o termofluido para produção de vapor a 11 bar funciona entre $250^{\circ} \mathrm{C}$ e $210^{\circ} \mathrm{C}$.

4) Considerou-se o poder calorífico inferior da biomassa como sendo 14374 $\mathrm{kJ} / \mathrm{kg}$, nas condições médias de humidade admitidas à fornalha.

5) Os custos dos permutadores de calor foram estimados admitindo permutadores de caixa e tubo e a função da área total foi estimada através dos coeficientes globais de transferência de calor listados na Tabela 4 . 


\begin{tabular}{|c|c|}
\cline { 2 - 2 } \multicolumn{1}{c|}{} & $\mathbf{U}, \mathbf{W m}^{-\mathbf{2}} \mathbf{K}^{-\mathbf{1}}$ \\
\hline Vapor-óleo & 300 \\
\hline Óleo-gases & 100 \\
\hline Gases-água & 120 \\
\hline
\end{tabular}

\subsection{A implementação computacional}

Dada a dificuldade de resolução dos modelos MINLP de grande dimensão, associada com a ocorrência de variáveis binárias e de funções não-convexas, visou-se diminuir o espaço de soluções possíveis, ou seja, reduzir-se o espaço de procura para o problema MINLP original. Obtém-se assim o problema MINLP-reduzido por introdução de restrições pertinentes, valores de corte (upper bounds), eliminação de configurações não-possíveis, fixação ou delimitação de variáveis binárias, como se descreve em seguida.

Consideraram-se vários aspetos de interesse (Daichendt e Grossmann, 1994) nomeadamente os relacionados com:

- O caráter de transexpedição (transshipment) dos fluxos caloríficospotencia a determinação do número total $K$ de estágios a considerar na superestrutura. Para tal, consideram-se os sucessivos intervalos entre as temperaturas de entrada das correntes de processo, quentes e frias, bem como o valor desejado para $\Delta T$ Tinin; ou seja,

\section{h.17}

$$
\left\{\begin{array}{l}
T h_{k} \in\left\{T_{i}, T I N_{j}+\Delta T \min \right\} \\
T c_{k} \in\left\{T I N_{j}, T I N_{i}-\Delta T \min \right\}, \quad \forall k \\
T h_{k}-T c_{k}=\Delta T \min
\end{array}\right.
$$

- A localização dos estágios (entrepostos) onde é possível considerar a ocorrência de permutas energéticas - para tal assinalando os intervalos de temperatura onde cada par $(i, j)$ de correntes quente e fria se encontram presentes.

As correntes de utilidades são tratadas como correntes de processo, respetivamente, quentes ou frias, generalizando o seu uso ao longo de todos os estágios onde sejam necessárias. Através de uma análise preliminar às trocas 
entre correntes, eliminam-se permutas impossíveis, impõem-se permutas necessárias ou conjugam-se as diversas alternativas. O procedimento para avaliação preliminar das alternativas (preliminar screening procedure) envolve:

1) A formulação de um modelo agregado, desenvolvido a partir do modelo MINLP original que é simplificado de forma a focalizar um dos seus subproblemas; por exemplo, evitando não-convexidades e obtendo um modelo MILP; ou ainda, fixando variáveis binárias e tratando um modelo NLP ou LP.

2) A determinação de uma solução inicial possível, desenvolvendo uma configuração-base para o subsistema energético, que permita o estabelecimento de um valor de corte (upper bound) para o subproblema de minimização dos custos.

3) A análise preliminar, utilizando o modelo agregado para delimitar o subconjunto de configurações que apresentem um valor-objetivo não superior ao custo daquela configuração-base.

4) A eliminação de configurações da superestrutura do problema MINLP original, obtendo-se uma superestrutura reduzida, à qual corresponde um espaço de procura também reduzido.

5) A resolução do problema MINLP com espaço de procura reduzido.

Quanto a aspetos do cálculo computacional, a igualdade h.9 padece de dificuldades numéricas quando as diferenças de temperatura $d T$ nas extremidades inicial e final do permutador em contracorrente forem similares, originando valores próximos de zero no denominador da fração em h.9. Nesse caso, aplicam-se as aproximações de Chen [1987] e Paterson [1984], respetivamente:

\section{h.18}

$$
\begin{aligned}
\operatorname{LMTD}_{i j} & \approx \sqrt[3]{\left.\left.d T\right|_{2} \cdot d T\right|_{1} \cdot\left(\frac{\left.d T\right|_{2}+\left.d T\right|_{1}}{2}\right)} \\
& \approx \frac{2}{3} \sqrt{\left.\left.d T\right|_{2} \cdot d T\right|_{1}}+\frac{1}{3}\left(\frac{\left.d T\right|_{2}+\left.d T\right|_{1}}{2}\right)
\end{aligned}
$$


Os aspetos específicos da rede são concretizados através da fixação ou delimitação de variáveis, ou mesmo adicionando novas restrições. Nomeadamente:

- As permutas proibidas ou requeridas configuram-se diretamente, forçando as variáveis binárias para os valores zero ou um, respetivamente.

- As restrições de projeto são diretamente incorporadas no modelo da superestrutura: por exemplo, uma permuta proibida (forbidden) é formulada anulando os valores das variáveis associadas, das quantidades energéticas permutadas e das áreas de transferência respetivas, ou mesmo igualando as temperaturas de entrada e saída das correntes nos permutadores proibidos.

- O número total de unidades de permuta (exchangers) é fixado ou delimitado superiormente através da soma das variáveis binárias,

h.19

$$
\sum_{i \in H} \sum_{j \in C} \sum_{k \in K} y_{i j k}+\sum_{i \in H} y c u_{i}+\sum_{j \in C} y h u_{j} \leq N e x c h^{U p p}
$$

- O número de partições das correntes é controlado delimitando o número de permutas em cada estágio; também pode não ser permitida qualquer partição, caso se requeiram permutas únicas para cada corrente em cada estágio:

h.20

$$
\begin{cases}\sum_{i \in H} y_{i j k} \leq 1, & \forall j, k \\ \sum_{j \in C} y_{i j k} \leq 1, & \forall i, k\end{cases}
$$

Note-se que a introdução de constrangimentos, embora providencie uma aproximação mais direta à situação real, origina uma perda de qualidade no objetivo económico. Deste modo, o modelo agregado ou o modelo reduzido conduzem sempre a configurações subótimas, as quais são úteis para promover a procura da melhor configuração, bem como para eliminar todas as configurações inferiores, num esquema sistemático e análogo ao branch-andbound.

Por outro lado, a consideração de um maior número de estágios na superestrutura permite a duplicação de permutas entre correntes e a utilização de um número maior de permutadores. Porém, o número de variáveis e 
restrições aumenta, o que se traduz num crescimento significativo do esforço computacional.

\subsection{Análise de resultados}

Usando as abordagens descritas analisou-se o sistema energético das duas unidades fabris localizadas em Tomar e na Nazaré. A abordagem sequencial baseada no método pinch foi aplicada em ambas as unidades. A abordagem de otimização simultânea foi utilizada apenas na análise do sistema energético de Tomar, não sendo aplicada na unidade da Nazaré.

A análise realizada à unidade da Nazaré, permitiu a implementação industrial de um novo sistema energético que conduziu a decréscimos no consumo energético específico e no custo de operação específico de $24 \%$ e 29\%, respetivamente, conforme reportaram Seita e outros (2009), obtendo-se também um menor impacto ambiental dos gases de combustão. Tal sistema é apresentado no diagrama da Figura 6 e corresponde à vista apresentada na Figura 7.

Nesta instalação da Nazaré, a configuração energética escolhida e implementada após o estudo de Integração de Processos é constituída por uma fornalha que produz os gases de combustão a partir apenas da biomassa e de alguns resíduos do processo.

Estes efluentes quentes vão aquecer um termofluido num permutador de calor. Os gases de combustão após esta troca de calor vão ainda ser usados no secador para redução do teor da humidade das fibras. O termofluido quente vai gerar posteriormente vapor de média pressão e água quente sob pressão.

Esta alternativa exigiu, para além da fornalha, três equipamentos de transferência de calor (aquecedor de óleo por serpentina, gerador de vapor de alta pressão e permutador de calor para água quente). Na Figura 7, apresentase uma vista da câmara de combustão (fornalha) e da unidade de recuperação de energia da fábrica de prensados de madeira da Nazaré, onde são aproveitados resíduos de madeira e biomassa para aquecimento do termofluido intermédio utilizado no aproveitamento térmico. 


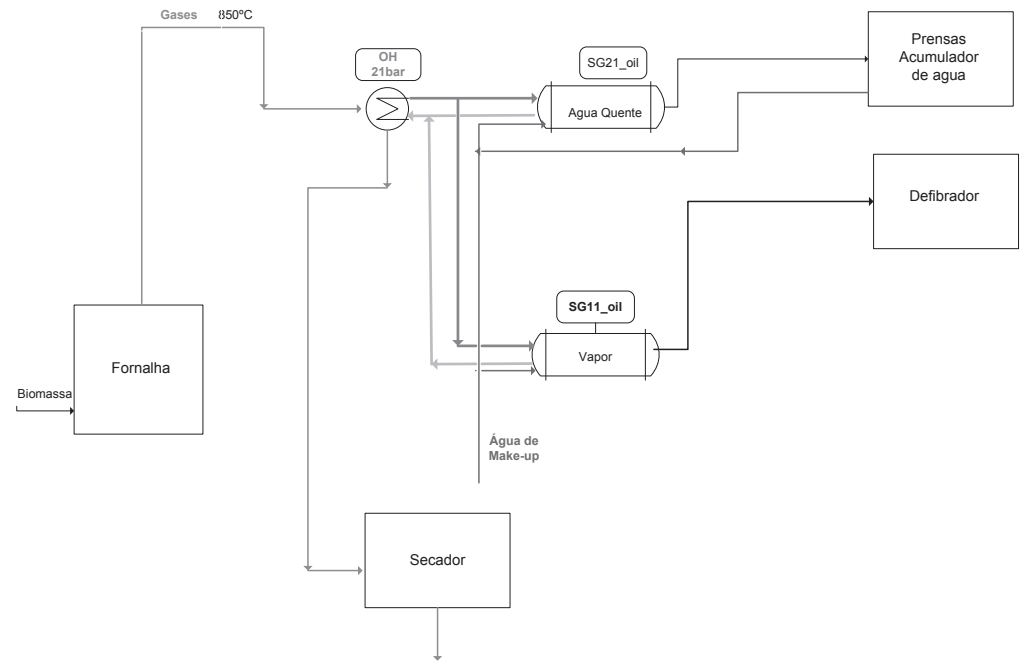

Figura 6 - Aproveitamento energético na instalação da Nazaré

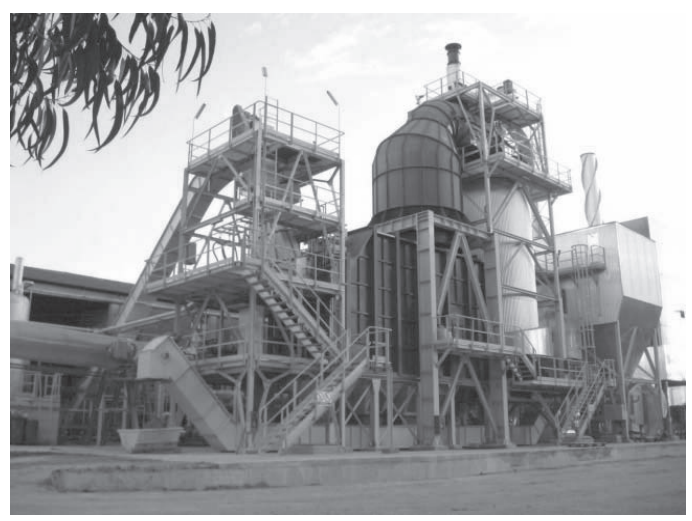

Figura 7 - Vista da câmara de combustão na unidade industrial de prensados de madeira da Nazaré (fonte: Seita e outros, 2009)

Para a unidade de Tomar, apresenta-se na Figura 8 o diagrama correspondente à melhor configuração obtida no âmbito da avaliação preliminar das alternativas (preliminar screening procedure). Neste cenário o vapor de mais alta pressão é produzido indiretamente através do termofluido, enquanto as restantes utilidades quentes são obtidas diretamente dos gases. Esta alternativa requer quatro equipamentos de transferência de calor com uma 
área estimada de cerca de $1700 \mathrm{~m}^{2}$. Os gases na saída da chaminé encontramse a $118^{\circ} \mathrm{C}$ e a eficiência energética global é de $94 \%$, determinando assim um consumo de biomassa da ordem das 5 ton/h.

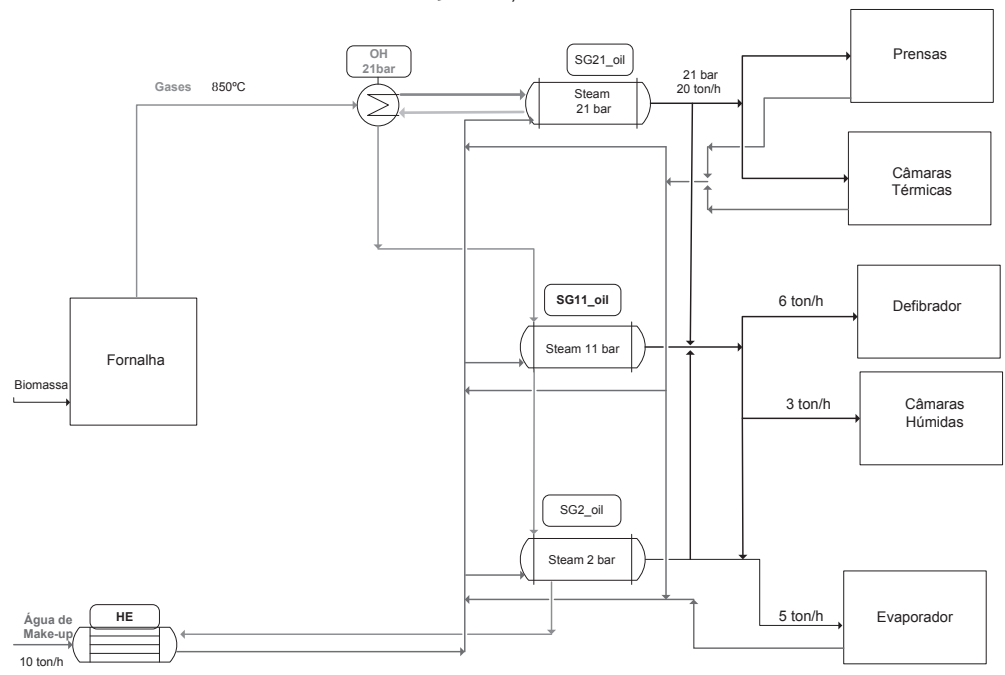

Figura 8 - Alternativa proposta para o estudo de Tomar com base na otimização simultânea.

Utilizou-se o ambiente GAMS, tendo sido selecionado o solver DICOPT, específico para MINLP. No âmbito da avaliação preliminar de alternativas, atendendo a restrições adicionais e à fixação de variáveis que permitem reduzir o espaço de procura, as versões do modelo minlp_simsup apresentam tempos de execução diminutos (inferiores a 10 segundos, em computador portátil ASUS-F3JC, com processador Intel Core2 T5500 a 1.55GHz e 2GB de RAM).

Em termos de comparação, como refere a Tabela 5, a abordagem sequencial baseada no método pinch e a avaliação preliminar da abordagem simultânea aplicadas ao sistema energético de Tomar conduzem à mesma qualidade de configurações. No entanto é bem conhecido que a avaliação preliminar de alternativas é apenas uma fase inicial, servindo de referência para melhorias subsequentes e visando soluções e configurações de superior qualidade. 
Tabela 5 - Matriz comparativa de abordagens.

\begin{tabular}{|c|c|c|}
\cline { 2 - 3 } \multicolumn{1}{c|}{} & Nazaré & Tomar \\
\hline Abordagem sequencial & $\begin{array}{c}\text { Conduziu a um novo } \\
\text { sistema de } \\
\text { reaproveitamento } \\
\text { energético! }\end{array}$ & $\begin{array}{c}\text { Qualidade inferior, } \\
\text { comparável a uma } \\
\text { avaliação preliminar por } \\
\text { MINLP. }\end{array}$ \\
\hline Abordagem simultânea & $\begin{array}{c}\text { Abordagem } \\
\text { não aplicada. }\end{array}$ & $\begin{array}{c}\text { Qualidade superior, mas } \\
\text { desenvolvimentos } \\
\text { descontinuados. }\end{array}$ \\
\hline
\end{tabular}

A abordagem através da modelação MINLP considera simultaneamente o consumo energético, bem como o custo de investimento em equipamentos (número e dimensão em área de transferência). Deste modo, perspetivam-se melhorias significativas relativamente à abordagem sequencial, onde a qualidade da solução para a escolha do equipamento depende da qualidade da solução da fase anterior relativa à recuperação de energia, e a dinâmica dos fatores económicos que lhes estão associados não é tratada. Ora, atente-se que a decisão de implementar uma unidade industrial depende não só da validade técnica como da oportunidade económica, pelo que é necessário proceder a uma constante apreciação dos diversos fatores económicos.

\section{Conclusões}

No âmbito da otimização e integração de processos, enquadrou-se um estudo na indústria de prensados de madeira. Este estudo constitui um elemento de apoio à decisão, a partir do qual serão detalhadas os projetos de integração energética, e cuja funcionalidade não depende diretamente da sofisticação matemática e computacional.

De facto, as duas abordagens à síntese de redes de permutadores de calor conduziram a situações distintas na Nazaré e em Tomar, embora os resultados numéricos sejam similares na parte em que podem ser comparáveis. No caso da Nazaré aplicou-se apenas a abordagem sequencial e implantou-se um novo sistema de aproveitamento energético, enquanto que em Tomar se aplicaram ambas as abordagens mas não ocorreram desenvolvimentos subsequentes. Há ainda que referir que: 
- A abordagem sequencial é baseada no método pinch, o qual se encontra bem estabelecido e reconhecido no meio industrial. A concretização de um maior aproveitamento energético dos gases de combustão na unidade da Nazaré possibilitou a redução de custos de energia primária, a redução de custos de operação, além de um menor impacto ambiental.

- A abordagem de otimização simultânea considera o consumo de utilidades e o custo de investimento, isto é, estabelece-se o compromisso entre o número de permutadores e a área total de transferência de energia em função da da recuperação de energia e da minimização das utilidades. Esta abordagem conduz a um modelo MINLP de resolução difícil, com aspetos computacionais exigentes, mas os respetivos resultados não foram concretizados em Tomar.

- Embora os processos industriais sejam diferentes nas duas unidades de prensados de madeira, o sistema energético em Tomar era similar ao da Nazaré. Para a unidade de Tomar, as configurações propostas em ambas as abordagens também foram algo semelhantes, pelo que os resultados de ambas as abordagens vieram a coincidir.

Os resultados obtidos servem de premissas para um projeto específico relativamente aos tipos de equipamento, dimensões e faseamento. Os resultados do estudo não foram implementados na unidade de Tomar pois, independentemente da qualidade das soluções e do modelo de programação matemática, não podemos negligenciar as dificuldades inerentes à aplicação de recursos num período económico em que tais recursos estão deveras limitados.

Na Nazaré, a utilização da fornalha encontra-se atualmente a cerca de metade do seu valor nominal, o que poderia ter sido evitado caso se tivesse utilizado um modelo de otimização simultânea com penalização do excesso de capacidades. Uma alternativa possível para uma utilização superior da fornalha considera a implantação de uma unidade para a produção de energia elétrica. Atendendo à validade e oportunidade de tal alternativa, a existência de um modelo que considere a otimização dos investimentos, em Programação Estocástica a Duas Fases ou até multifase, pode contribuir para a robustez da decisão e constitui um novo desafio. 


\section{Nomenclatura}

\section{Índices e conjuntos}

$C$ - Conjunto de correntes frias, $j$ (Cold);

$H$ - Conjunto de correntes quentes, $i$ (Hot);

$i$ - Corrente quente, $i$;

$j$-Corrente fria, $j$;

$k$ - Intervalo de temperatura (estágio da superestrutura), $k$;

$K$ - Conjunto dos intervalos de temperatura (estágios), $k$;

\section{Parâmetros}

$\Delta T$ Tmin -Diferença mínima de temperaturas;

$C c u(j)$ - Custo unitário da utilidade fria, $j$;

$C F$ - Custos de investimento de natureza fixa, referentes a permutadores entre correntes quentes e frias $(i j)$, ou equipamentos de utilidades quentes $(h u)$ ou frias $(c u)$

$C h u(i)$ - Custo unitário da utilidade quente, $i$;

$C V$ - Custos de investimento de natureza variável, para a permutadores entre correntes quentes e frias $(i j)$, equipamentos de utilidades quentes $(h u)$ ou frias $(c u)$

$d T^{u p p}$ - Limite superior (upper bound) para a diferença de temperatura entre correntes quentes e frias;

$F C p$ - Conteúdos caloríficos da correntes, quentes $i$ ou frias $j$;

$N C$ - Número de correntes frias $j($ Cold $)$;

$N E x c h{ }^{u p p}$-Limite superior (upper bound) para o número de unidades de permuta;

$\mathrm{NH}$ - Número de correntes quentes $i(H o t)$;

$N K$ - Número de intervalos de temperatura (estágios da superestrutura), $k$;

$Q^{u p p}$ - Limite superior (upper bound) para a energia permutada entre correntes quentes e frias;

$T I N$ - Temperaturas de entrada das correntes, quentes $i$ ou frias $j$

TOUT - Temperaturas de saída das correntes, quentes $i$ ou frias $j$;

$U_{i j}$ - Coeficiente global de transferência entre a corrente quente $i$ e fria $j$;

\section{Variáveis}

$A c u_{i}$ - Área de transferência para o arrefecimento da corrente quente $i$ pelas utilidades frias;

$A h u_{j}$ - Área de transferência para o aquecimento da corrente fria $j$ pelas utilidades quentes;

$A_{i j}$ - Área de transferência para a permuta entre a corrente quente i e a corrente fria j;

$d T$ - Diferenças de temperatura entre correntes quentes e frias;

$d T c u_{i}$ - Diferença de temperatura no arrefecimento da corrente quente $i$ pelas utilidades frias;

$d T h u_{j}$ - Diferença de temperatura no aquecimento da corrente fria $j$ pelas utilidades quentes;

$d T_{i j}$ - Diferença de temperatura na permuta entre a corrente quente $i$ e a corrente fria $j$;

$L M T D_{i j}$ - Diferença de temperatura logarítmica média (log mean temperature difference) na permuta entre as correntes $i$ e $j$; 
$Q c u_{i},-$ Consumo de utilidades frias no arrefecimento da corrente quente $i$;

$Q h u_{j}$ - Consumo de utilidades quentes no aquecimento da corrente fria $j$;

$Q_{i j}$ - Energia permutada entre a corrente quente $i$ e a corrente fria $j$;

$Q_{i j k}$ - Energia permutada entre cada corrente quente $i$ e as correntes frias $j$ ao longo dos diversos estágios $k$;

$T$ - Temperaturas das correntes quentes $i$, correntes frias $j$, dos diversos estágios $k$;

$y c u_{i}$ - Variáveis binárias referentes ao arrefecimento da corrente quente $i$ por utilidades frias;

$y h u_{j}$ - Variáveis binárias referentes ao aquecimento da corrente fria $j$ por utilidades quentes;

$y_{i j k}$ - Variáveis binárias para a permuta entre a corrente quente $i$ e a correntes fria $j$ no estágio $k$;

\section{Agradecimentos}

Os autores agradecem os dados fornecidos pelas empresas do Grupo Investwood situadas em Tomar e Famalicão da Nazaré, nomeadamente ao Engenheiro Costa Cabral e Engenheira Alexandra Gouveia pelo apoio técnico fornecido na recolha de dados. Os autores também agradecem aos revisores anónimos, cujas sugestões muito contribuíram para valorizar este artigo.

\section{REFERÊNCIAS}

ADENE/DGEG, Relatório Interno, Fevereiro de 2008

Cerda, J., Westerberg, A., "Synthesizing Heat Exchanger Networks Having Restricted Stream/Stream Matches Using Transportation Problem Formulations", Chemical Engineering Science, Vol. 38, 1983, 1723-1740

Daichendt, M., Grossmann, I.E., "Preliminary Screening Procedure for the MINLP Synthesis of Process Systems - II.Heat Exchanger Networks", Computers and Chemical Engineering, Vol. 18, 1994, 679-709

Daichendt, M., Grossmann, I.E., "Integration of hierarchical decomposition and mathematical programming for the synthesis of process flowsheets", Computers and Chemical Engineering, Vol 22, 1997, 147-175

Damours, S., Feng, Y, LeBel, L., Nourelfath, M., "Integrated Bio-refinery and Forest Products Supply Chain Network Design", Proceedings of IFORS2011 - 19th Conference for the International Federation of Operational Research Societies, Melbourne, Australia, July-2011, 15

Direcção-Geral da Energia e dos Transportes / Comissão Europeia, Fazer mais com menos Livro Verde sobre a eficiência energética, Serviço das Publicações Oficiais das Comunidades Europeias, 2005

Drobež, R., Pintari冈, Z.N., Pahor, B., Kravanja, Z., "Simultaneous heat integration and the synthesis of biogas processes from animal waste", Asia-Pacific Journal of Chemical Engineering, Vol. 6, 2011, 734-749 
Erlenkotter, D., Manne, A.S., "Capacity Expansion For India`s Nitrogenous Fertilizer Industry", Management Science, Vol. 14, n. ${ }^{\circ}$ 10, June-1968, B553-B572

Flisberg, P., Damours, S., Ronnqvist, M., Troncoso, J.J., Weintraub, A., "Integrated Value Chain Planning", Proceedings of IFORS2011 - 19th Conference for the International Federation of Operational Research Societies, Melbourne, Australia, July-2011, 20

Furman, K.C., Sahinidis, N.V., "Computational Complexity of Heat Exchanger Network Synthesis", Computers and Chemical Engineering, Vol. 25, 2001, 1371-1390

Gassner, M., Marechal, F, "Methodology for the optimal thermo-economic, multi-objective design of thermochemical fuel production from biomass", Computers and Chemical Engineering, Vol. 33, 2009, 769-781

Linnhoff, B., Townsend, D.W., Boland, D., Hewitt, G.F., Thomas, B.E.A., Guy, A.R., Marsland, R.H., A User Guide On Process Integration For The Efficient Use Of Energy, The Institution of Chemical Engineers, Rugby, 1982

Magueijo, V., Fernandes, C., Matos, H., Pedro Nunes, C., Calau, J.P., Oliveira, F., Carneiro, J., Medidas de eficiência Energética aplicáveis à indústria Portuguesa: um enquadramento tecnológico sucinto, ADENE-Agência para a Energia, 2010

Martín, M., Grossmann, I.E., "Energy optimization of hydrogen production from lignocellulosic biomass", Computers and Chemical Engineering, Vol. 35, 2011, 1798- 1806

Miranda, J.L., Casquilho, M.A.S., "Robust optimization in Heat Exchanger Network", Proceedings of ICEEM2007-2nd International Conference of Energy, Environment and Energy Management, University of Extremadura, Badajoz, Spain, June-2007, 4pp

Relvas, S., Matos , H., Fernandes, M.C., Castro, P., Pedro Nunes, C., "Aquo Min: A Software tool for Mass-Exchange Networks targeting and design", Computers and Chemical Engineering, Vol. 32, 2008, 1085-1105

Saboo, A.K., Morari, M., Colberg, R.D., "RESHEX: an interactive software package for the synthesis and analysis of resilient heat-exchanger networks - I.Program description and application", Computers and Chemical Engineering, Vol. 10, 1986, 577-589

Seita, A., Matos, H., Fernandes, M.C., "Process Integration in a Biomass based Industrial Plant", CibBB2009-Conference on Industry-based Bioenergy and Biorefinery, INETI, Lisboa, 19-20 Novembro, 2009

Soršak, A., Kravanja, Z. "Simultaneous MINLP synthesis of heat exchanger networks comprising different exchanger types", Computers and Chemical Engineering, Vol. 26, 2002, 477-775

Yee, T.F., Grossmann, I.E., "Simultaneous Optimization Models for Heat Integration - II.Heat Exchanger Network Synthesis", Computers and Chemical Engineering, Vol. 14, 1990, 1165-1184 